ВІСНИК

ОДЕСЬКОГО НАЦІОНАЛЬНОГО

МОРСЬКОГО УНІВЕРСИТЕТУ

№ 1 (61), 2020
HERALD

OF THE ODESSA NATIONAL

MARITIME UNIVERSITY

№ $1(61), 2020$

УДК 621.346

DOI 10.47049/2226-1893-2020-1-87-96

\title{
ЗНИЖЕННЯ МЕХАНІЧНИХ ВТРАТ У СУДНОВИХ СЕРЕДНЬООБЕРТОВИХ ДИЗЕЛЯХ ЗА РАХУНОК ОПТИМІЗАЦЇ̈ РОБОТИ ЦИРКУЛЯЦИЙНИХ СИСТЕМ МАЩЕННЯ
}

\author{
C.B. Сагін
}

доктор технічних наук, доцент

Національний університет «Одеська морська академія»

Анотація. Розглянути питання забезпечення мінімального рівня механічних втрат у суднових середньообертових дизелях. Наведені результати визначення механічного коефіиієнту корисної дії дизеля 6ЕY22AW фірми Yаптаг у діапазоні його навантаження 35-80\% та різних умовах експлуатації його системи ииркуляиійного мащення. Експериментально доведено, щзо при оптимальному поповненні ииркуляційної системи та додавання в обсяг ииркуляиійної системи мащення поверхнево-активної присадки з оптимальною концентрацією забезпечується 5,8-11,1\%-е зниження механічних втрат, що відображається в пропориійному збільшенні механічного коефімієнта корисної дії дизеля.

Ключові слова: судновий дизель, механічні втрати, механічний коефічієнт корисної дії, система мащення, поверхнево-активна присадка.

\section{УДК 621.346}

DOI 10.47049/2226-1893-2020-1-87-96

\section{СНИЖЕНИЕ МЕХАНИЧЕСКИХ ПОТЕРЬ В СУДОВЫХ СРЕДНЕОБОРОТНЫХ ДИЗЕЛЯХ ПУТЕМ ОПТИМИЗАЦИИ РАБОТЫ ЦИРКУЛЯЦИОННЫХ СИСТЕМ СМАЗЫВАНИЯ}

\author{
С.В. Сагин
}

доктор технических наук, доцент

Національний університет «Одеська морська академія»

Аннотация. Рассмотрены вопросы обеспечения минимального уровня механических потерь в судовых среднеоборотных дизелях. Приведены результаты определения механического коэффициента полезного действия дизеля 6ЕY22AW фирмы Yаптаг в диапазоне его нагрузки 35-80\% и различных условиях эксплуатации его системы цииркулячионного смазывания.

(C) Сагин C.B., 2020 
Экспериментально доказано, что при оптимальном пополнении цุиркуляиионной системь и добавления в объем цүиркуляџионной системь смазки поверхностно-активного присадки с оптимальной концентрацией обеспечивается 5,8-11,1\%-е снижение механических потерь, которое выражается в пропорциональном увеличении механического коэффициента полезного действия дизеля.

Ключевые слова: судовой дизель, механические потери, механический коэффициент полезного действия, система смазывания, поверхностно-активная присадка.

\author{
UDC 621.346 \\ DOI 10.47049/2226-1893-2020-1-87-96
}

\title{
REDUCTION OF MECHANICAL LOSSES IN MEDIUM-SPEED MARINE DIESEL ENGINES BY OPTIMIZING THE OPERATION OF CIRCULATING LUBRICATION SYSTEMS
}

\author{
S. Sagin \\ doctor of technical sciences, assistant professor \\ National University «Odessa Maritime Academy»
}

\begin{abstract}
It is pointed out that the energy complexes of river and marine means of transport are complex structural objects, in operation of which it is necessary to provide not only requirements for obtaining efficient power and maintaining ecological parameters, but also a minimum level of mechanical losses during the conversion of input energy into useful work. According to the information search, structural and technological measures to reduce mecha-nical energy losses during the operation of marine diesels are based on: modification of the surfaces of the cylinder group, ensuring minimum fuel consumption, regeneration of the properties of the working surfaces of the main elements of the diesel. At the same time, the most accessible in the conditions of diesel operation is the optimization of the circulation of lubrication systems. The questions of ensuring the minimum level of mechanical losses in marine medium-speed diesel engines are considered. The results of determination of mechanical efficiency of Yanmar 6EY22AW diesel engine in the range of its load 35-80\% and various conditions of operation of its circulating lubrication system are presented. It is experimentally proven that the reduction of mechanical losses is estimated directly by the proportional increase in the mechanical efficiency of the diesel engine. This parameter when operating Yanmar 6EY22AW diesel without the use of surface additives in the circulating lubrication system and with a standard oil refill period is $80,3 \pm 0,2 \%$. The choice of the optimal mode of replenishment of the circulatory system, as well as the addition to the total volume of the circulating system of the surface additive with the optimal concentration (the determination of which
\end{abstract}


is carried out by preliminary laboratory studies), contributes to the increase of the mechanical efficiency of the diesel - that is, to reduce the mechanical losses and increase the effective power. With an optimum replenishment of the circulatory system (which according to experimental studies is 10 hours) and adding to the volume of the circulating lubricant additive system (with an optimum concentration of $0.1 \%$ by the total volume of the system), it is possible 5,8-11,1\% reduction of mechanical losses. For Yanmar 6EY22AW marine diesel (which has been piloted), it achieves a mechanical efficiency of $89,1 \pm 0,2 \%$.

Keywords: marine diesel, mechanical losses, mechanical efficiency, circulating lubrication system, surface-active additive.

Постановка проблеми в загальному вигляді. Енергетичні комплекси річкових і морських засобів транспорту є багатокомпонентними структурними об'єктами, при цьому:

- їх функціонування починається 3 прийому на борт судна робочих рідин (палива, мастила, води);

- їх основним експлуатаційним завданням $\epsilon$ перетворення потенційної енергії робочих рідин на корисну роботу, що забезпечує або рух судна, або вироблення теплової та електричної енергії;

- завершальним етапом їх виробничого циклу є видалення відпрацьованих газів і охолоджувальних рідин у довкілля [1].

При цьому необхідно забезпечувати не тільки вимоги щодо отримання ефективної потужності і підтримки екологічних параметрів, але й мінімальний рівень механічних втрат при перетворенні вхідної енергії на корисну роботу.

Механічні втрати енергії при передачі корисної (індикаторної) потужності від суднового двигуна внутрішнього згоряння (ДВЗ) до споживача лежать у широких межах і можуть становити 6-10\% - у разі експлуатації ДВ3 на номінальному режимі, і до $100 \%$ - під час експлуатації на холостому ходу. Рівень механічних втрат оцінюється механічним коефіцієнтом корисної дії (ККД). Мінімізації цих втрат і забезпечення мінімальних значень протягом тривалого часу $є$ актуальним завданням, на розв'язання якого спрямовано наукові дослідження, що проводяться як дизелебудівними корпораціями, так і окремими наукововиробничими фірмами та інститутами [2].

Аналіз останніх досліджень і публікацій. Конструкційні та технологічні заходи, що забезпечують зниження механічних втрат енергії під час експлуатації суднових ДВЗ, розглядалися в різних роботах. При цьому увага приділялася модифікації поверхонь циліндро-поршневої групи [3], забезпеченню мінімальної витрати палива [4], загальній методології оцінки енергетичних витрат [5], регенерації властивостей робочих поверхонь основних елементів дизеля [6]. 
Постановка завдання. Аналіз досвіду проектування та експлуатації суднових пропульсивних комплексів, що забезпечують мінімальний рівень механічних втрат, показує, що їх вдосконалення доцільно вести за наступними напрямками: підвищення стійкості роботи деталей кривошипно-шатунного механізму (КШМ) і підшипників руху; зниження втрат енергії за рахунок підвищення пружнодемпфуючих властивостей мастильного матеріалу, що забезпечує процеси змащування i охолодження КШМ i підшипників, a також працездатний стан колінчастого валу і лінії валопроводу; мінімізація гідравлічних втрат і контактних навантажень у паливній апаратурі високого тиску; розвиток методів діагностики технічного стану вузлів і деталей дизеля, а також функціональних характеристик робочих рідин, що забезпечують отримання корисної роботи; удосконалення методів, що сприяють зниженню термічних і динамічних навантажень на рухомі і нерухомі деталі дизеля i валопроводу. Найбільшим доступним в умовах експлуатації вже існуючого енергетичного обладнання $\epsilon$ оптимізація роботи циркуляційних систем мащення.

Виклад основного матеріалу дослідження. 3 цілого ряду методів, що $є$ найбільш прийнятними для суднових умов (з технологічної та фінансової точки зору), є використання оптимального доливання мастила в систему і застосування поверхнево активних речовин (ПАР) [7].

Вплив інтенсивності доливання моторного мастила в загальний об'єм циркуляційної системи мащення на механічні втрати енергії можливо оцінити за зміною механічного ККД дизеля для різних умов експлуатації (різних умов поповнення системи мащення свіжим мастилом). Для цього виконувалось вимірювання механічного ККД на різних режимах роботи дизелів 6ЕY22AW (що відповідають 35-ти, 50-ти, 65-ти і 80-ти \%-ому навантаженню) за різної інтенсивності поповнення системи мащення: 1-й дизель - через 100, 2-й - через 25, 3-й - через 10 годин роботи. На кожному 3 досліджуваних режимів $\left(0,35 N_{\text {еном}}, 0,5 N_{\text {еном}}\right.$, $\left.0,65 N_{\text {еном}}, 0,8 N_{\text {еном }}\right)$ дизелі експлуатувалися рівний проміжок часу, який залежно від навантаження суднової електростанції становив 1,5-2,5 години. Зміна навантаження на двигуни за цей час не перевищувало $\pm 2,5 \%$, а отриманий масив значень механічного ККД дозволяв із високою точністю визначити його середне значення. Принципова схема системи циркуляційного мащення дизелів надана на рис. 1.

У результаті були отримані значення, узагальнені у вигляді табл. 1, за результатами якої побудована діаграма, що наведена на рис. 2.

Наведені в таблиці 1 і на рис. 2 результати підтверджують зниження механічних втрат енергії при скороченні часу між доливанням мастила в обсяг циркуляційної системи. 
ВІСНИК

ОДЕСЬКОГО НАЦІОНАЛЬНОГО

МОРСЬКОГО УНІВЕРСИТЕТУ

№ 1 (61), 2020
HERALD

OF THE ODESSA NATIONAL

MARITIME UNIVERSITY № $1(61), 2020$



Рис. 1. Схема модернізації ичиркуляційної системи мащуення суднових дизелів 6ЕY22AW фірми Yаптаг під час проведення експерименту:

1 -мастильний насос; 2 - мастильний фільтр тонкого очищення;

3 -магістраль відведення парів мастила і повітря; 4 - витратомір;

5 - дозатор присадки; 6-мастильний фільтр грубого очищення;

7 - відділювач мастила; 8-магістраль підведення мастила

Таблиия 1

Зміна механічного ККД суднових дизелів 6ЕY22AW фірми Yanтаr за різних умов експлуатації

\begin{tabular}{|l|c|c|c|c|}
\hline \multirow{2}{*}{ Умови експлуатації } & \multicolumn{4}{|c|}{ Навантаження на двигун } \\
\cline { 2 - 5 } & $0,35 N_{\text {еном }}$ & $0,5 N_{\text {еном }}$ & $0,65 N_{\text {еном }}$ & $0,8 N_{\text {еном }}$ \\
\hline $\begin{array}{l}\text { Двигун № 1 } \\
\text { (поповнення через 100 годин) }\end{array}$ & 0,743 & 0,803 & 0,842 & 0,872 \\
\hline $\begin{array}{l}\text { Двигун № 2 } \\
\text { (поповнення через 25 годин) }\end{array}$ & 0,806 & 0,821 & 0,862 & 0,882 \\
\hline $\begin{array}{l}\text { Двигун № 3 } \\
\text { (поповнення чере3 10 годин) }\end{array}$ & 0,823 & 0,837 & 0,873 & 0,891 \\
\hline
\end{tabular}

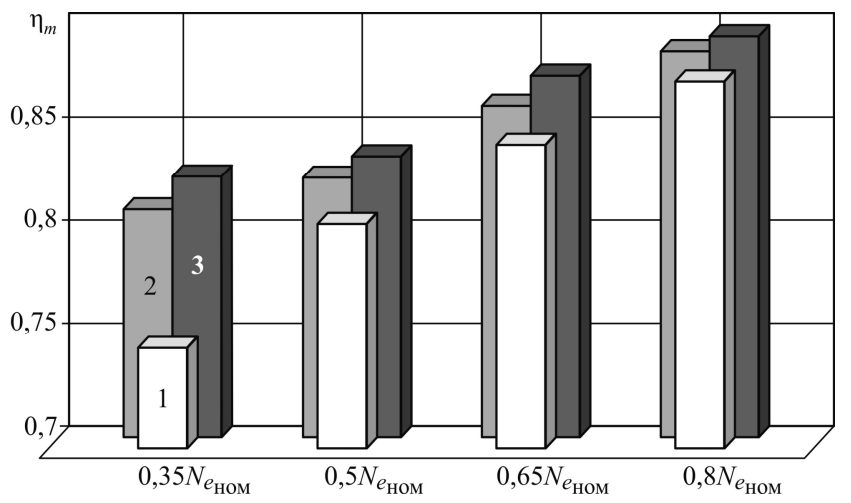

Рис. 2. Зміна механічного ККД суднового дизеля 6ЕY22AW фірми Yanтаг за різної інтенсивності доливання мастила:

1 - через 100 годин; 2 - через 25 годин; 3 - через 10 годин 
Наведені в таблиці 1 і на рис. 2 результати підтверджують зниження механічних втрат енергії при скороченні часу між доливанням мастила в обсяг циркуляційної системи.

Для визначення впливу ПАР на механічні втрати суднових середньообертових дизелів експерименти отримали наступне продовження [8]. Як і в попередній серії експериментів, дизелі експлуатувалися на рівновеликому навантаженні (250-750) $\pm(15-45)$ кВт, однакову кількість часу 12-15 годин/добу.

Технологічна послідовність проведення експериментів полягала в наступному. Перший дизель був «контрольним», і після заміни мастила в його системі мащення інших технічних заходів з ним не проводилося, $\mathrm{i}$ відповідно до вимог заводу-виготовлювача його експлуатація здійснювалася протягом 100 годин роботи без проміжного поповнення мастила в системі. За цей період експлуатації кількість мастила в циркуляційній системі дизеля не знижувалась нижче гранично допустимого значення. При цьому в циркуляційній системі з точністю $\pm(2,5-3)$ \% підтримувалися постійний тиск і температура мастила. Система мащення другого дизеля поповнювалася свіжим мастилом через кожні 10 годин роботи до верхнього рекомендованого в картері дизеля, що відповідало максимально можливому обсягу мастила в системі. Даний період поповнення було визначено в якості оптимального під час проведення попередніх експериментів. Система мащення третього дизеля спочатку заповнювалася мастилом з поверхнево активною присадкою (ПАП), що містить у своєму складі солі міді. Оптимальна концентрація присадки становила $0,1 \%$ від обсягу мастила в системі мащення і була встановлена за допомогою попередніх оптичних і триботехнічних досліджень [9]. Крім того, через кожні 10 годин роботи здійснювалося поповнення циркуляційної системи мащення даного дизеля мастилом 3 такою ж концентрацією ПАП, як і в загальному обсягу системи, що забезпечувалося і контролювалося за допомогою дозуючого пристрою i витратоміра (позиції 5 і 6 на рис. 1).

Аналогічно попередній серії експериментів, для кожного дизеля в діапазоні навантажень $(0,35-0,8) N_{\text {еном }}$ виконувалося визначення механічного ККД. Результати цих експериментів наведені в таблиці 2 та надані на рис. 3.

Таблиия 2

Зміна механічного ККД суднових дизелів 6ЕY22AW фірми Yаптаг за різних умов експлуатаиії

\begin{tabular}{|l|c|c|c|c|}
\hline \multirow{2}{*}{ Умови експлуатації } & \multicolumn{4}{|c|}{ Навантаження на двигун } \\
\cline { 2 - 5 } & $0,35 N_{\text {еном }}$ & $0,5 N_{\text {eном }}$ & $0,65 N_{\text {еном }}$ & $0,8 N_{\text {eном }}$ \\
\hline Поповнення через 100 годин & 0,743 & 0,803 & 0,842 & 0,872 \\
\hline Поповнення через 10 годин & 0,823 & 0,837 & 0,873 & 0,891 \\
\hline $\begin{array}{l}\text { Поповнення через 10 годин } \\
\text { і добавка ПАП }\end{array}$ & 0,852 & 0,864 & 0,887 & 0,906 \\
\hline
\end{tabular}






Рис. 3. Зміна механічного ККД суднового дизеля 6ЕY22AW фірми Yanтаr за різної інтенсивності доливання мастила:

1 - робота системи мащення в штатному режимі; 2 - поповнення системи мащення через 10 годин роботи; 3 - поповнення системи мащення через 10 годин роботи і додавання поверхнево активної присадки

Висновки і перспективи подалыших досліджень. Із цілого ряду методів зниження механічних втрат у суднових середньообертових дизелях найбільш прийнятними для суднових умов (з технологічної та фінансової точки зору) є використання оптимального доливання мастила в систему циркуляційного мащення і застосування поверхнево активних речовин. Перший (доливання мастила) рекомендовано заводомвиготовлювачем, але, як правило, розроблено для номінального режиму роботи дизеля за умови його експлуатації за стандартних умов. Другий (застосування присадок) не має широкого розповсюдження через необхідність додаткових досліджень та розробки спеціальних рекомендацій, що враховують особливості експлуатації дизелів на різних експлуатаційних режимах, а також у випадках зміни одного сорту палива на інший.

Зниження механічних втрат оцінюється прямо пропорційним зростанням механічного ККД дизеля. Цей параметр при роботі дизеля 6EY22AW фірми Yanmar без використання ПАП у циркуляційній системі мащення та при нормативному терміні поповнення системи мастилом дорівнює $80,3 \pm 0,2 \%$. Вибір оптимального режиму поповнення циркуляційної системи, а також додавання в загальний обсяг циркуляційної системи поверхнево-активної присадки 3 оптимальною концентрацією (визначення якої здійснюється попередніми лабораторними дослідженнями), сприяє збільшенню механічного ККД дизеля - тобто зниженню механічних втрат та збільшенню ефективної потужності.

При оптимальному поповненні циркуляційної системи (яке відповідно до експериментальних досліджень складає 10 годин) та 
ВІСНИК

ОДЕСЬКОГО НАЦІОНАЛЬНОГО

МОРСЬКОГО УНІВЕРСИТЕТУ

№ 1 (61), 2020
HERALD

OF THE ODESSA NATIONAL

MARITIME UNIVERSITY

№ 1 (61), 2020

додаванням до обсягу циркуляційної системи мащення ПАП (з оптимальною кон-центрацією $0,1 \%$ за загальним обсягом системи) можливо 5,8-11,1\%-е зниження механічних втрат, що для суднового дизеля 6ЕY22AW фірми Yanmar (на якому виконувалися експериментальні дослідження) забезпечує досягнення значення механічного ККД на рівні 89,1士0,2\%.

\section{СПИСОК ЛІТЕРАТУРИ}

1. Kuropyatnyk O. A. Exhaust Gas Recirculation as a Major Technique Designed to Reduce NOx Emissions from Marine Diesel Engines / O.A. Kuropyatnyk, S.V. Sagin // OUR SEA: International Journal of Maritime Science \& Technology, 2019. Vol. 66. Iss. 1. P. 1-9.

2. Голіков В.А. Розвиток сучасної теорії $і$ практики технічної експлуатації морського і річкового флоту: конщепиії, методи, технології / В.А. Голіков, О.А. Онищенко // Судовые энергетические установки: Научн.-техн. сб. 2017. № 37. Одесса: $H У$ «OMA». C. 13-27.

3. Сагин С.В. Определение триботехнических характеристик поверхностей по степени упорядоченности пристенных слоев углеводородных жидкостей / С.В. Сагин, Ю.В. Заблоикий // Проблеми техніки: Наук.-виробн. журнал. 2011. № 3. Одесса: OHMУ. C. 78-88.

4. Sagin S.V. Estimation of Operational Properties of Lubricant Coolant Liquids by Optical Methods / S.V. Sagin, V.G. Solodovnikov // International Journal of Applied Engineering Research. 2017. Vol. 12. Num. 19. P. 8380-8391.

5. Сагин С.В. Оптические характеристики граничных смазочных слоев масел, применяемых в ииркулячионных системах судовых дизелей / С.В. Сагин, Д.В. Мачкевич // Судовые энергетические установки: Научн.-техн. сб. 2011. № 26. Одесса: OHMA. C.116-125.

6. Levchenko V.A. Orientational ordering in 2, 6-lutidine near quartz surfaces modified by carbon / V.A. Levchenko, A.Yu. Popovskii // Journal of Molecular Liquids. 2000. T. 85. № 1-2. C. 211-217.

7. Поповский А.Ю. Комплексная оченка эксплуатационных характеристик смазочных углеводородных жидкостей / А.Ю. Поповский, С.В. Сагин // Автоматизачия судовых технических средств: Научн.-техн. сб. 2014. Bып. 20. С. 74-83.

8. Поповский А.Ю. Оченка эксплуатационных свойств смазочноохлаждаюших жидкостей судовых технических средств / А.Ю. Поповский, С.В. Сагин // Автоматизация судовых технических средств: Научн.-техн. сб. 2016. Bып. 22. С. 66-74. 
9. Zablotsky Yu.V. Enhancing Fuel Efficiency and Environmental Specifications of a Marine Diesel When using Fuel Additives / Yu.V. Zablotsky, S.V. Sagin // Indian Journal of Science and Technology. December 2016. Vol. 9. Iss. 46. P. 353-362. DOI: $10.17485 / i j s t / 2016 / v 9 i 46 / 107516$.

\section{REFERENCES}

1. Kuropyatnyk O.A., Sagin S.V. (2019) Exhaust Gas Recirculation as a Major Technique Designed to Reduce NOx Emissions from Marine Diesel Engines. OUR SEA : International Journal of Maritime Science \& Technology, vol. 66, no. 1, pp. 1-9. doi.org/ 10.17818/NM/2019/1.1.

2. Golikov V.A., Onishchenko O.A. (2017) Rozvytok suchasnoyi teoriyi i praktyky texnichnoyi ekspluataciyi morskogo i richkovogo flotu: koncepciyi, metody, texnologiyi [Development of modern theory and practice of technical exploitation of the sea and river fleet: concepts, methods, technologies]. Sudovye energeticheskie ustanovki : nauchno-tehnicheskij sbornik, no. 37, pp. 13-27.

3. Sagin S.V., Zablotsky Yu.V. (2011) Opredelenie tribotehnicheskih harakteristik poverhnostej po stepeni uporyadochennosti pristennyh sloev uglevodorodnyh zhidkostej [Determination of tribolo-gical characteristics of surfaces according to the degree of ordering of wall layers of hydrocarbon fluids]. Problemy texniky: naukovo-vyrobnychj zhurnal, no. 3, pp. 78-88.

4. Sagin S.V., Solodovnikov V.G. (2017) Estimation of Operational Properties of Lubricant Coolant Liquids by Optical Methods. International Journal of Applied Engineering Research, vol. 12, no. 19, pp. 8380-8391.

5. Sagin S.V., Matskevich D.V. (2011) Opticheskie harakteristiki granichnyh smazochnyh sloev masel, primenyaemyh $v$ cirkulyacionnyh sistemah sudovyh dizelej [Optical characteristics of boun-dary lubricating layers of oils used in marine diesel circulating systems]. Sudovye energeticheskie ustanovki: nauchnotehnicheskij sbornik, no. 26, pp. 116-125.

6. Levchenko V.A., Popovskii A.Yu. (2000) Orientational ordering in 2, 6-lutidine near quartz surfaces modified by carbon. Journal of Molecular Liquids, vol. 85, no. 1-2, pp. 211-217.

7. Popovskii A.Yu., Sagin S.V. (2014) Kompleksnaya ocenka ekspluatacionnyh harakteristik smazochnyh uglevodorodnyh zhidkostej [Comprehensive performance assessment of lubricating hydrocar-bon fluids]. Avtomatizaciya sudovyh tehnicheskih sredstv: nauch-no-tehnicheskij sbornik, no. 20, pp. 74-83. 
ВІСНИК

ОДЕСЬКОГО НАЦІОНАЛЬНОГО

МОРСЬКОГО УНІВЕРСИТЕТУ

№ 1 (61), 2020
HERALD

OF THE ODESSA NATIONAL

MARITIME UNIVERSITY

№ 1 (61), 2020

8. Popovskii A.Yu., Sagin S.V. (2016) Ocenka ekspluatacionnyh svojstv smazochno-ohlazhdayushih zhidkostej sudovyh tehnicheskih sredstv [Evaluation of the operational properties of cutting fluids of marine technical equipment]. Avtomatizaciya sudovyh tehnicheskih sredstv: nauchno-tehnicheskij sbornik, no. 22, pp. 66-74.

9. Zablotsky Yu.V., Sagin S.V. (2016) Enhancing Fuel Efficiency and Environmental Specifications of a Marine Diesel When using Fuel Additives. Indian Journal of Science and Technology, vol. 9 , no. 46, pp. 353-362. DOI: 10.17485/ijst/2016/v9i46/107516.

Стаття надійшла до редакиії 24.01.20

Посилання на статтю: Сагін С.В. Зниження механічних втрат у суднових середньообертових дизелях за рахунок оптимізації роботи циркуляційних систем мащення // Вісник Одеського національного морського університету: Зб. наук. праць, 2020. № 1(61). C. 87-96. DOI 10.47049/2226-18932020-1-87-96.

Article received 24.01.20

Reference a JournalArtic: Sagin, S. Reduction of mechanical losses in medium-speed marine diesel engines by optimizing the operation of circulating lubrication systems // Herald of the Odessa national maritime university. 1(61), 87-96. DOI 10.47049/2226-1893-2020-1-87-96. 